\title{
El ocaso del autor. Una perspectiva sobre los escritos autobiográficos de Rousseau.
}

Gabriela Domecq*

Resumen: Este trabajo se propone leer la obra autobiográfica de Rousseau como el resultado de un litigio que opone al escritor y al público. Ambos se disputan la identidad del autor. Veremos que el proyecto autobiográfico nace como una reivindicación de la soberanía de autor sobre el texto pero culmina instituyendo la soberanía del lector. En el transcurso de la obra autobiográfica de Rousseau el autor deviene un efecto de la lectura.

Palabras Clave: Autor, autobiografía, público, opinión

Abstract: This paper aims to read the autobiographical work of Rousseau as the outcome of a dispute between the writer and the public. Both parts dispute the author's identity. We will see that the autobiographical project starts as the claim of sovereignty of the work by the author, but culminates by establishing the sovereignty of the reader. In the autobiographical writings, the author is an effect of the reading.

Key words: Author, autobiography, public, opinion.

* Docente investigadora de la Universidad Nacional de General Sarmiento. Doctora en filosofía por la Universidad de París 8. Tradujo el Contrato Social y el Manuscrito de Ginebra para Colihue Clásica, ha publicado varios artículos dedicados a la obra de Rousseau. Dirección electrónica: domecqgabriela@gmail.com. 
"Cada quien me figura a su fantasía, sin temor a que el original venga a desmentirle. Había un Rousseau en el gran mundo, y otro en el retiro que no se le parecía en nada." Rousseau, Bosquejo de las Confesiones. ${ }^{1}$

"La escritura es ese lugar neutro, compuesto, oblicuo, al que va a parar nuestro sujeto, el blanco y negro en donde acaba por perderse toda identidad, comenzando por la propia identidad del cuerpo que escribe." Barthes, La muerte del autor. ${ }^{2}$

En los escritos autobiográficos, Rousseau parece resistirse a la perdida que conlleva el lugar de la escritura. El cuerpo que escribe se afana por preservar la identidad del autor. El autor parece presentir su muerte, "la muerte del autor" que el bello texto de Barthes describe y consagra.

Vincular los textos autobiográficos de Rousseau con La muerte del autor es hacer una relación peligrosa. Es exponernos a la ceguera de una lectura obnubilada por los espejismos del anacronismo. La omnipresencia del autor en los textos mencionados, su afán por mantener el dominio sobre su identidad y a partir de allí sobre la obra, concuerdan mal con la desaparición del autor descripta por Barthes. Pero ese afán por preservar la identidad y reivindicar su unicidad ¿no puede ser acaso leído como la muerte del autor, al menos como el presentimiento de la fragilidad de su existencia cercada por el trabajo de la escritura que borra la identidad y la publicación del texto que la

\footnotetext{
${ }^{1}$ Rousseau, Fragments autobiographiques, en CEuvres complètes I, Paris, Gallimard, 1959, p. 1151.

2 Barthes, Le bruissement de la langue, en Essais critiques IV, Paris, Seuil, 1984.
} 
entrega al dominio del público? En los textos autobiográficos de Rousseau, el autor ¿no revela ya su litigiosa existencia?

La muerte nunca ha preocupado a Rousseau; el dominio ejercido por el público sobre su identidad y su obra, en cambio, obsesionó los últimos años de su vida. Los textos autobiográficos manifiestan esta obsesión. La adulteración de sus libros, los pasquines publicados en su nombre, los crímenes que se le imputan, son interpretados como una estrategia concertada para desfigurar al autor y así hacer desaparecer su obra. La adulteración de los libros, pero sobre todo los crímenes que difaman al autor ponen en peligro su memoria y con ella la integridad de la obra. La identidad del autor aparece en la obra autobiográfica como una identidad en litigio cuyo dominio, reivindicado por el escritor, es en los hechos ejercido por el público. Las Confesiones y los Diálogos surgen como un intento desesperado por arrancarle al público su dominio y restablecer la soberanía del autor.

Reivindicar la soberanía del autor ¿no es conjurar su muerte? ¿No es aferrarse a ese lugar del cual la escritura lo excluye, pero en el cual una visión común de la literatura lo reclama?

En este trabajo no indagaremos sobre la intencionalidad que Rousseau atribuye al público, ni tampoco buscaremos dilucidar en qué medida la locura puede haber instigado esta obsesión por la integridad de la identidad del autor. Dejaremos al psicólogo la facultad de determinar el delirio de quien sostiene la pluma, nos concentraremos en la obra para mostrar que en los textos autobiográficos el empeño del escritor por restablecer la soberanía del autor sobre su identidad es el preludio de su muerte. No pretendemos afirmar aquí que en Rousseau estaría ya presente la conciencia que en la escritura es el lenguaje y no el autor él que habla, ni tampoco vemos en él la voluntad de suprimir al autor en beneficio de la escritura como lo ensayará Mallarmé en su poética. En los textos autobiográficos sin embargo, dos rasgos funcionan, para nosotros, como preludio de lo que más tarde Barthes llamará "la muerte del autor". Por un lado, el hecho de que paulatinamente la omnipresencia del autor se va acotando al espacio abierto por la lectura. Mostraremos que la soberanía y la unicidad reivindicadas por el autor van dejando el lugar al lector. La identidad del autor, conquistada al final de los Diálogos, es un efecto de la lectura. Veremos que es el lector quien restituye la unicidad del autor. 
Pero esta unicidad deja de ser una realidad extra-textual para transformase en un efecto de la lectura. El segundo rasgo que para nosotros preludia la muerte del autor es el desapego hacia el público y la indiferencia por la suerte de la obra que se producen en los últimos textos autobiográficos. En las Ensoñaciones la escritura es soberana, se libera de la justificación del autor y con ella, de los apremios del público.

\section{El oficio de autor}

Rousseau ubica el origen de sus desgracias en el momento en que se hizo autor. "Todo el resto de mi vida y de mis desgracias fue el efecto inevitable de ese instante de extravío". ${ }^{3}$ Ese instante fatídico es aquel en que, alentado por Diderot, ${ }^{4}$ decide concursar por el premio de la Academia de Dijon. La participación a ese concurso se vuelve nefasta porque al ganarlo, el texto que sometió al jurado es publicado. La publicación del Discurso sobre las ciencias y las artes lo hace autor, y un autor "de moda". ${ }^{5}$

Ser autor no es haber tenido la "inspiración de Vincennes", cuyas ideas dieron origen al Discurso sobre las artes y las letras. No son ni la inspiración, ni las ideas, ni tampoco el acto de escribir que definen al autor. Rousseau se transforma en autor cuando hace imprimir su escrito y en ese acto le da un público. A partir el siglo XVII la lengua francesa ${ }^{6}$ asocia al autor, en el campo de las letras, con aquel que ha hecho imprimir un escrito, distinguiéndolo del

${ }^{3}$ Confessions, pp. 351-352. Todas las referencias a la obra de Rousseau siguen las Oewvres complètes editadas en París por Gallimard en la colección La Pléiade. Les Confessions, Rousseau juge de Jean Jacques, Dialogues y Les rêveries du promeneur solitaire se encuentran en el tomo I (1959). Las traducciones de los fragmentos son nuestras. A partir de ahora citaremos respectivamente, Confessions, Dialogues et Rêveries.

${ }^{4}$ Confessions, pp. 351-352.

${ }^{5}$ Confessions, p. 363: “... no hay otro ejemplo de un éxito igual [escribe Diderot a Rousseau luego de la publicación del primer Discurso]". "El éxito de mis primeros escritos me había puesto de moda" (Ibid., p. 367).

${ }^{6}$ Richelet, Dictionnaire Francois (1680), la segunda definición de autor es "aquel que ha compuesto algún libro impreso". Furetière, Le dictionnaire universal (1690), quinta entrada de autor: "en literatura se dice de todos aquellos que han puesto a la luz algún libro. Ahora sólo se dice de aquellos que lo han hecho imprimir". 
hombre de letras que se define por su independencia de espíritu y la pertenencia a la sociedad de la gente de letras. ${ }^{7}$ ¿Cómo explicar que la publicación convierta en nefasta a la condición del autor?

A partir del siglo XVII la constitución de un mercado del impreso modifica la condición social del autor. El escritor sin rango ni bienes accede a la categoría de autor sin depender exclusivamente del mecenazgo. El mercado del impreso permite la profesionalización de la actividad literaria, a la vez que cambia la percepción estética de la obra. La obra se transforma en un bien negociable cuyo creador-propietario puede esperar un beneficio pecuniario. Pierde, en tanto objeto de contrato y de equivalencia monetaria, la inconmensurabilidad que por otra parte conserva como "obra de arte". La inconmensurabilidad de la obra, su valor, se explica a partir de la creatividad y originalidad del autor. La producción literaria es investida de una estética de la originalidad a partir de la cual el texto adquiere una identidad referida inmediatamente a la subjetividad del autor. ${ }^{8}$ R. Chartier resalta el lazo paradójico que une la profesionalización de la actividad literaria, que debe entrañar una remuneración directa que permita a los escritores vivir de su pluma, y la auto-representación de los autores en una ideología del genio propio, fundada en la autonomía del gesto creador. ${ }^{9}$ Sumemos a esta paradoja que el mercado, al fomentar la proliferación del impreso y ampliar el origen social del escritor, conspira contra la estética que promueve y el valor del oficio de autor. En efecto, la proliferación del impreso banaliza la obra, y la remuneración hace de la actividad literaria un trabajo para vivir. El mercado, al permitir vivir de la pluma, abre la posibilidad para que aquel que necesita trabajar para vivir pueda dedicarse a la actividad literaria. El oficio de autor contradice la representación tradicional del hombre de letras que no vive de su pluma sino de sus bienes o de sus cargos y desprecia el impreso como una banalización de la obra. ${ }^{10}$

\footnotetext{
7 Voltaire, "Gens de lettres", Dictionnaire philosophique, Paris, Baudouin frères, éditeurs, 1827, p. 364. Chartier, R., "Que es un autor?", en Libros, lecturas y lectores en la edad moderna, Madrid, Alianza, 1993, pp. 71-74.

${ }^{8}$ Chartier, R., op. cit., p. 68.

${ }^{9}$ Ibid., p. 69.

${ }^{10}$ Ibid., p. 70.
} 
El estigma del trabajo que acompaña al "oficio de autor" se refleja en el artículo "Gens de lettres" del Dictionnaire philosophique de Voltaire:

Cien autores compilan para tener pan, y veinte folliculaires ${ }^{11}$ hacen un resumen, la crítica, la apología, la sátira de esas compilaciones, con la idea también de tener qué comer, porque no tienen un oficio. [...] La desgracia de esa gente proviene de que sus padres no le han hecho aprender una profesión: es un gran defecto del orden moderno. Todo hombre del pueblo que puede educar a sus hijos en un arte útil, y no lo haga merece un castigo. El hijo de un carpintero se hace jesuita a los diecisiete años. A los veinticuatro lo echan de la Compañía, porque el desorden de sus costumbres llama demasiado la atención. Y ahí lo tenemos, sin pan. Se hace folletinista (folliculaire), infecta la baja literatura y se convierte, incluso, en desprecio y horror de la canalla. ¡Y a ésos se les llama autores $!^{12}$

Para Voltaire los infelices autores están sometidos, a diferencia del hombre de letras, a una triple calamidad: la rapacidad de los libreros, los celos de los iguales y el juicio de los necios.

La estética del genio convive con el desprestigio de la condición del autor. La profesionalización de la actividad literaria a la vez que asegura el sustento del escritor, banaliza su producción y lo somete a la doble dependencia de los libreros y de los necios. La apertura de la actividad literaria a "cualquiera" por la profesionalización, y la banalización de la obra por su reproducción en el mercado como cualquier bien, agudizan la tensión entre la identidad del autor y el valor de la obra. Para que la obra sea valorada, el escritor tiene que poner en juego su singularidad, tiene que poder reflejar en ella su originalidad; socialmente, sin embargo, el autor es cualquiera. Coexiste una estética que hace radicar en la subjetividad el autor el valor de la obra, y un contexto social que estigmatiza al autor por ser un trabajador más.

Rousseau al igual que Voltaire reacciona contra la banalización y la profesionalización de la actividad literaria, pero por razones diferentes. Para

\footnotetext{
${ }^{11}$ Término despectivo que designaba a aquello periodistas sin talento ni escrúpulos; se encuentra en desuso en el francés moderno. Traducción aproximada: "folletinista". ${ }^{12}$ Voltaire, "Auteur", Dictionnaire philosophique, Tome II, Paris, De l'imprimerie de la société littéraire typographique, 1785, pp. 400-402.
} 
Rousseau no es el origen social lo que conspira contra el valor de la obra, no distingue al hombre de letras del autor. En su crítica, el hombre de letras es autor, ambos se caracterizan por el sometimiento voluntario al gusto del público. ${ }^{13}$ Para el autor como para el hombre de letras, la pasión por distinguirse prima por sobre la búsqueda de la verdad, la virtud y la belleza. Si Rousseau rechaza el oficio de autor no es porque trabajar para vivir descalifique en sí la actividad literaria. Él es parte de esa gente del pueblo sobre la cual recaen los sarcasmos de Voltaire. El problema que plantea a Rousseau la condición de autor es otro. El autor está sometido a una doble alienación. La primera, que podríamos llamar "voluntaria", acontece cuando el escritor somete su pluma al gusto del público; la segunda, que llamaremos "inevitable", consiste en el dominio que adquiere el público sobre la persona del autor. Rousseau pudo sortear la primera; su obra autobiográfica es un intento casi desesperado por escapar de la segunda.

Rousseau preserva su autonomía como escritor haciéndose de un oficio que no someta su pluma a la obligación de escribir. ${ }^{14}$ Rechaza cargos y pensiones. Para preservar su independencia se hace copista de música. ${ }^{15}$ Rousseau, a la vez que reconoce su condición, tiene que trabajar para vivir, reivindica su derecho a escribir y el valor de sus libros. Pero no lo hace desde la perspectiva de la estética del genio. No es su genialidad que da valor a sus libros sino su motivación: "decir la verdad a los hombres". Lo que lo mueve a escribir libros, no es ni la venalidad del folletinista, ni las pretensiones del hombre de letras, sino el amor a la verdad, a la justicia y a la utilidad pública. Rousseau contrapone al "cualquiera genial" de la estética del genio, el cualquiera que está "forzado por un estímulo más fuerte que el interés e

13 Dialogues, p. 841, Dialogues, pp. 917-918. Véase también, "Lettres à D’Alembert", CEuvres complètes, V, Paris, Gallimard, 1995, pp. 18-19.

14 Dialogues, p. 839: "Pensar es para mí un trabajo penoso, que me cansa, me atormenta y me disgusta... Si algunas veces me gusta pensar es libremente y sin condicionamientos... Pero pensar en esto o aquello por deber, por oficio, poner en mis producciones corrección, método, es para mí el trabajo de un galeote, pensar para vivir me parece la más penosa y a la vez la más ridícula de todas las ocupaciones."

${ }^{15}$ Confessions, p. 363: "En la independencia en la que quería vivir había que subsistir. Imagine un medio muy simple, fue de copiar música a tanto la página.” 
incluso que la gloria"16. Invierte la estética antes descripta, el libro adquiere valor por la urgencia que lo sostiene, no por la singularidad del escritor. ${ }^{17} \mathrm{El}$ autor desaparece tras el afán de verdad y de justicia. La verdad, la justicia y la utilidad pública se interponen entre el impreso y la identidad del autor. El autor desaparece tras ellas.

$\mathrm{Al}$ rechazar el oficio de escritor y renunciar a la vanidad del hombre de letras, Rousseau busca garantizar el valor de su obra. El impreso reconquista la inconmensurabilidad de la obra de arte por la mediación de la verdad y la justicia. ${ }^{18}$ Pero no logra sin embargo preservar a la obra de los avatares de la condición del autor. A pesar de la ética del escritor, la obra queda atrapada por la visibilidad del autor. La obra es amenazada por la sombra del autor desfigurado por el público. ${ }^{19}$

Entre el escritor devenido autor y su identidad se interpone la opinión del público. El autor no depende del público solamente porque determine el precio que el librero esté dispuesto a pagar por el manuscrito, sino más fundamentalmente porque en última instancia es su creación. El autor se hace un nombre cuando a través del escrito que hace imprimir es "tomado" por el público. Fiel a la perspectiva abierta por la estética de la originalidad, el público busca al autor detrás de la obra. Esa búsqueda hace del autor su creación. La urgencia de los escritos autobiográficos nace para Rousseau del dominio que el público ejerce sobre la identidad del autor.

Una anécdota relatada en las Confesiones grafica el dominio que el público adquiere sobre el autor y la perturbación que esto provoca en el escritor. En el libro VIII, Rousseau relata la escena que vivió en el Café du

\footnotetext{
16 Dialogues, p. 673.

17 "Una fuerte convicción ha ocupado siempre el lugar de la elocuencia, y siempre escribí sin vigor y mal cuando no estuve profundamente convencido" (Carta a M. de Malesherbes, 12/1/1762).

18 Confessions, pp. 402-403: “...siempre pensé que la condición de autor era, y sólo podía ser, ilustre y respetable si no era un oficio. Es muy difícil pensar noblemente cuando se piensa para vivir. Para poder, para atreverse a decir grandes verdades no hay que depender del éxito".
}

19 Dialogues, pp. 693-695. 
grand commun al día siguiente del ensayo del Adivino de la aldea ${ }^{20}$. Cuenta Rousseau que ese día había mucha gente en el café y se hablaba del ensayo. Entre los presentes se destaca un oficial que se jactaba de haber visto el ensayo y al autor de la obra. El oficial relata a los presentes el ensayo y los dichos del autor. Rousseau comenta:

Lo que me maravilló de aquel relato, hecho con tanta certeza como simplicidad, fue, que no había ni una sola palabra que fuera verdadera. Me quedaba muy claro que aquel que hablaba tan sabiamente del ensayo, no había estado, pues tenía ante sus ojos sin reconocerlo al Autor que decía haber visto tanto. ${ }^{21}$

Rousseau se sorprende del efecto que esta escena tiene sobre él. El personaje lo fascina y lo llena de vergüenza: "me interesaba a pesar de su descaro y a pesar de mí: mientras profería sus mentiras, yo enrojecía, bajaba los ojos, estaba con el alma en vilo; buscaba si no había una manera de creer en el error y de buena fe". ${ }^{22}$

Rousseau sale del café temiendo delatar al mentiroso. Ya en la calle descubre que está bañado en sudor. ¿Es por vergüenza ajena? ¿O bien es la conmoción por haber descubierto que la identidad del autor ha dejado de pertenecerle?

En un bosquejo de las Confesiones que no será integrado a la versión definitiva, Rousseau explica que una de las razones que lo lleva a escribir las Confesiones es el dominio del público sobre la identidad del autor: "Porque mi nombre debe durar entre los hombres no quiero que lleve una reputación engañosa (...)". ${ }^{23} \mathrm{La}$ circulación de sus libros hace que cada uno lo imagine según su fantasía: "Nada era más diferente de mí que ese retrato; yo no era mejor si se quiere, pero era otro. No se me hacía justicia ni en el bien, ni en el mal". ${ }^{24}$

\footnotetext{
${ }^{20}$ Confessions, p. 376.

${ }^{21}$ Confessions, p. 377. Respetamos el uso de las mayúsculas hecho por Rousseau.

22 Confessions, p. 377.

23 Fragments autobiographiques, Oeuvres complètes I, p. 1153.

${ }^{24}$ Ibid., p. 1151.
} 
Para rectificar la imagen idealizada como la imagen monstruosa con la cual los unos atacan su carácter y los otros inventan sus virtudes, emprende las Confesiones: prefiere que sus defectos sean conocidos a perdurar bajo la imagen de un "personaje" que le es ajeno. ${ }^{25}$ Rousseau se propone restituir la identidad del autor a partir de la unicidad de la historia del escritor. A través de las Confesiones el público podrá reconstruir la verdad del autor. El escritor lo hace pasar tras bastidores, dice Rousseau, para que, con todos los resortes de su vida a la vista, pueda reconstruir la identidad del autor, y el autor pueda verse reflejado en el público.

\section{El autor versus el público: de las Confesiones a los Diálogos}

La autobiografía al igual que la biografía, el relato histórico o el artículo periodístico, es un texto referencial, aporta una información sobre una realidad exterior al texto. Su finalidad no es la verosimilitud, sino la semejanza con la realidad. Sin embargo, en tanto género literario su especificidad radica en que la referencia está subordinada a una dimensión interna al texto. La autobiografía no se define por su referencialidad. No es el relato de los hechos verificables lo que define a la autobiografía, si así fuera no podríamos distinguirla de la biografía o del relato histórico. La especificidad de la autobiografía radica según entendemos a partir del trabajo de Philippe Lejeune, ${ }^{26}$ en la identidad entre el nombre propio de la cubierta, el narrador y el personaje de quien se habla. El nombre propio de la cubierta remite a la existencia del autor, es la única señal en el impreso de una realidad extratextual. El autor aclara Lejeune "no es una persona, es una persona que escribe y publica a caballo entre lo extra-textual y el texto, línea de contacto entre ambos". 27

La autobiografía es un texto paradójico, remite a una realidad extratextual que se sustenta en un nombre propio cuya existencia sólo se verifica en la portada del libro. A través de la autobiografía el autor, que solo existe

\footnotetext{
${ }^{25}$ Ibid., p. 1153.

${ }^{26}$ Lejeune, Ph., Le pacte autobiographique, Paris, Seuil, 1975.

${ }_{27}$ Lejeune, Ph., "El pacto autobiográfico", Suplementos Anthropos, No 29, Barcelona, diciembre 1991, p. 51.
} 
por los libros publicados, reivindica su existencia extra-textual. La semejanza entre esa realidad extra-textual (la vida y personalidad del autor) y el relato producido, se fundan sin embargo en un hecho que solo existe en los márgenes del texto: la identidad postulada, implícita o explícitamente, entre el autor, el narrador y el personaje. El texto producido para ser identificado como autobiografía supone la identidad explícita entre el sujeto de la enunciación y el sujeto del enunciado, y de manera segundaria el parecido a nivel del enunciado. El parecido es una cuestión de hecho sujeta a discusión; la identidad, una cuestión de derecho que define al género. Puede suceder que el sujeto de la enunciación altere, voluntaria o involuntariamente los hechos, sin que esa identidad con el sujeto del enunciado sea alterada. El análisis propuesto por $\mathrm{Ph}$. Lejeune, busca definir a la autobiografía como un texto referencial cuya especificidad o "identidad" se definen a partir de la realidad textual de la obra. El pacto autobiográfico es la afirmación en el texto de la identidad del nombre de la portada (el autor), el narrador y el personaje. El lector puede poner en cuestión el parecido entre el personaje y la realidad extra-textual, pero no la identidad que une el nombre de la portada, el narrador y el personaje. Esta identidad es indiscutible. Lejeune precisa: "Cuando para distinguir la ficción de la autobiografía, se trata de determinar a qué remite el yo de las narraciones personales, no hay necesidad de referirse a una imposible referencialidad extra-textual: el mismo texto ofrece a fin de cuentas ese último término, el nombre propio del autor a la vez textual e indudablemente referencial. Si está referencia es indudable es porque está fundada en dos instituciones: el estado civil y el contrato de publicación." 28 No hay razón alguna concluye Lejeune para dudar de su identidad.

Los textos autobiográficos de Rousseau verifican los análisis de Lejeune en cuanto podemos identificar con facilidad el pacto autobiográfico y la voluntad de referencialidad que inspira al texto: decirlo todo. Sin embargo, la lógica de los textos invierte la jerarquía entre la referencia y la identidad. El nombre propio no puede funcionar como referencia indudable porque su identidad está en manos del público. El texto autobiográfico tiene como propósito restituir la unicidad del nombre propio. Rousseau intentará reconstruir la referencia indudable del nombre propio a través del personaje

${ }^{28}$ Ibid., p. 56. 
del enunciado. El relato autobiográfico deberá aportar la prueba de la identidad, y de la unicidad del autor.

En los textos autobiográficos de Rousseau, podemos reconocer la posición del autor como esa línea que une y separa al texto de la referencia extra textual, y a la vez conspira contra el proyecto autobiográfico. El nombre propio de la portada al estar "a caballo entre el texto y lo extra-textual" da lugar a que el público se interponga entre el texto y la realidad extra-textual. La realidad paradójica del autor parece deshacer la unión entre el texto y la referencia extra textual que el escrito autobiográfico busca unir. El público y el escritor se disputan la tarea de reconstruir la unión entre el texto y la referencia. El dominio del público estará en la opinión, el escritor tratar de restituir al autor el suyo a través del texto autobiográfico.

El público accede al autor a través del nombre propio inscripto en la portada de los libros, pero ejerce su dominio sobre la realidad extra-textual a la que el nombre remite. Esa línea tenue que une el texto a la referencia mediante el nombre del autor se desdibuja. El autor es desfigurado por el público, su identidad al igual que su obra dejan de pertenecerle. Poco importa que la animosidad del "público" haya sido real o delirada, lo relevante para nosotros es que los textos autobiográficos se organizan en torno a esta presencia que amenaza la existencia del autor. Ante la omnipotencia del público, ni el estado civil, ni el contrato de publicación prueban la existencia extra-textual del autor. Rousseau relata en los Diálogos cómo es transformado en un monstruo por el público y cómo ve su nombre proliferar en libros que no ha escrito.

En la obra autobiográfica de Rousseau, el público se intercala en esa línea que une al texto con la realidad extra-textual comprometiendo la existencia del autor y dejando a la autobiografía en el lugar de la novela.

El público en tanto substantivo remite en el Diccionario de la Academia Francesa de 1762 al pueblo en general. En los textos de Rousseau adquiere una fisonomía más precisa. Si tuviéramos que definirlo a partir de los textos teóricos podríamos ver en el público la personificación de la opinión. El lugar de la opinión en la configuración del ethos social es uno de los tópicos más novedosos de Rousseau, aunque poco explorados por la 
crítica. $^{29}$ No podemos detenernos aquí sobre esta noción, pero importa señalar que el público en tanto personificación de la opinión pública no se confunde con los lectores. El público designa la influencia de la opinión en la configuración de la vida social. ${ }^{30}$ Cuando cada uno opina por sí mismo, la opinión pública surge de la libre contraposición de las opiniones particulares. Así formada, la opinión pública conforma lo que Rousseau llama les lumières publiques. ${ }^{31}$ Cuando la opinión está dominada por una pequeña elite y ya nadie opina por sí mismo, la opinión pública es la expresión de la alienación. Los Diálogos ponen en escena esta alienación a través del rol que juegan Les Messieurs en la dirección del público:

Entre las singularidades que distinguen al siglo en el que vivimos de todos los demás está el espíritu metódico y consecuente que dirige las opiniones públicas. Hasta ahora esas opiniones erraban sin consecuencia y sin regla al son de las pasiones de los hombres, pasiones que entrechocándose hacían flotar al público de una a la otras sin ninguna dirección constante. Hoy ya no es así. Incluso los prejuicios tienen su dirección y sus reglas, y esas reglas a las cuales el público está sometido sin darse cuentas se establecen únicamente a partir del punto de vista de aquellos que lo dirigen. ${ }^{32}$

\subsection{El trabajo de la escritura}

Rousseau emprende la historia de su vida con la idea de "actuar" sobre el público. Pretende enfrentar la opinión dirigida contra él con el relato de su vida. Tiene que reconstruir mediante el relato autobiográfico esa línea que une al texto con la realidad extra-textual del autor. Quiere restituir esa realidad tal cual es. Emprende esta tarea con la clara conciencia de que su empresa es

\footnotetext{
${ }^{29}$ Bernardi, B., « Rousseau et la généalogie du concept d'opinion publique », SVEC, 2012 : 01, pp. 95-127.

30 Dialogues, p. 841: “Cuando publicaba mis primeros escritos, todavía librado a sí mismo, (el público) no había totalmente adoptado ninguna secta y podía escuchar la voz de la verdad y de la razón. Pero hoy, totalmente subyugado, ya no piensa, no razona, ya no es nada por sí mismo, sólo sigue las impresiones que le dan sus guías".

31 Contrat Social, II, Euvres complètes, III, Paris, Gallimard, 1964, p. 380.

32 Dialogues, p. 964.
} 
única. La unicidad de su obra autobiográfica radica en la determinación de la forma por el contenido: decirlo todo. Rousseau diferencia sus memorias de las obras autobiográficas que lo preceden, en que en ellas no pretende presentar una imagen elogiosa del autor sino decirlo todo: "Seré verídico, lo seré sin reservas; diré todo; lo bueno y lo malo, todo". ${ }^{33}$ Para decirlo todo no basta con restituir todos los hechos, el trabajo de la escritura deberá acercar esa realidad única al lector.

Las Confesiones serán el relato despiadado de los hechos, sentimientos y pensamiento que han forjado el carácter del autor. Pero no basta con querer confesarlo todo, es necesario que la escritura en su forma sostenga la verdad de la confesión. El contenido tiene que encontrar su forma, la escritura tiene que poder decirlo todo sin maquillar al autor:

Para lo que tengo que decir habrá que inventar un lenguaje tan nuevo como mi proyecto: pues ¿cuál es el tono?, ¿qué estilo tomar para desentrañar el caos inmenso de sentimientos tan diversos, tan contradictorios, muchas veces viles y otras sublimes, por los cuales sin tregua fui afectado? ¿Cuántas nimiedades, cuantas miserias tendré que exponer $(\ldots)$ ? $^{34}$

El lenguaje de las Confesiones tiene que sortear dos escollos, la particularidad de su objeto y la tentación de la literatura. Rousseau no se propone hacer el relato de su vida sino transcribir la historia de su alma. ${ }^{35}$ Tiene que restituir el caos de los sentimientos, las contradicciones que lo agitan, las miserias y las pequeñas nadas que, sedimentándose, configuran el "raro y singular ensamblaje que forma su carácter". ${ }^{36} \mathrm{Si}$ alguna pieza de esta historia falta, todo estará perdido, será imposible "develar" la particularidad del carácter. La escritura tiene que reproducir el caos y a la vez no dejar rastro, seguir las tribulaciones del alma y desaparecer tras ellas:

Si quiero hacer un texto escrito con cuidado como los demás, no me describiría, me engalanaría. Aquí está en cuestión mi retrato, no un libro.

\footnotetext{
33 "Ébauches des Confessions", Fragments autobiographiques, p. 1153.

34 Ibid., p. 1153.

35 Ibid., p. 1150.

36 Ibid., p. 1153.
} 
Quiero trabajar en la cámara oscura para así decir; no es necesario otro arte que el de seguir los trazos que veo marcados. Tomé partido tanto en relación al estilo como a las cosas. No me esforzaré por volverlos uniforme; diré cada cosa como las siento, como la veo, sin sofisticación, sin sufrimiento, sin atormentarme por las contradicciones. (...) mi estilo, desigual y natural, unas veces conciso y otras difuso, algunas sabio y otras loco, a veces grave y otras alegre, será por sí mismo parte de mi historia. ${ }^{37}$

El estilo es parte de la historia. No se trata de hacer un libro sino dejar que la escritura se desarme para adoptar el pulso de las cosas. La búsqueda de una escritura que se quiere desarmada: desigual y natural, rápida y difusa, loca y sabia a la vez, se explicita en los bosquejos a las confesiones pero podemos encontrar sus rastros a lo largo de toda la obra autobiográficos. En las Ensoñaciones Rousseau anuncia: "Estas hojas no serán más que un informe diario de mis ensoñaciones. Diré lo que he pensado así como me ha llegado, y con tan poca ligazón como la que tienen de costumbre las ideas de la víspera con las de mañana".38

En los Diálogos la construcción del texto forma parte de la estrategia explicitada por el autor. Tiene que poner en escena sus conjeturas, tiene que mostrar cómo "si fuera otro", hubiera tratado a alguien como él. Construye un diálogo entre personajes imaginarios. Sin embargo la escritura vuelve a aparecer desarmada. La gran tristeza que provocan en él los hechos relatados le impide releer y corregir. Los Diálogos son, según su autor, un texto excesivamente largo, lleno de repeticiones, de ideas sin la forma apropiada, sin orden. Aquí "el sentimiento vivo de todas las desgracias"39 se impone a la escritura y la ahoga.

Esta escritura despojada de los artificios de la literatura deja al lector la tarea de componer el relato que restituya la identidad del autor. La tarea del escritor es hacer que el alma se haga transparente al lector: "Quisiera poder de alguna manera volver el alma transparente a los ojos del lector, y para eso busco mostrársela bajo todos los puntos de vista, iluminarla, lograr que no

\footnotetext{
${ }^{37}$ Ibid., p. 1154.

38 Rêveries, p. 1000.

${ }^{39}$ Dialogues, p. 665.
} 
haya ningún movimiento que él no pueda percibir, con el fin que pueda juzgar por sí mismo sobre el principio que los produce". ${ }^{40}$

La transparencia no es una cualidad del alma. La escritura no se hace transparente porque pierde la opacidad del signo. La escritura hace que el alma se vuelva transparente porque al multiplicar las perspectivas y copiar sus movimientos pone al lector en el lugar del autor, y al escritor en el lugar de Dios: "Develé mi interior tal como lo has visto tú mismo [Dios]". ${ }_{41}$

La identidad tiene la contingencia de la historia. No es una esencia, se configura a partir de los hechos vividos, los sentimientos experimentados, los pensamientos. No hay ni unidad, ni unicidad de la identidad fuera del relato que cada uno reconstruye. Las Confesiones, ese gran fresco del alma, tienen que llevar al lector a reconocer al autor. La identidad confiscada por el público tiene que ser restituida por el lector:

Si me encargara del resultado y le dijese: éste es mi carácter, podría creer que lo engaño o que me equivoco. Al detallarle con simplicidad todo lo que me ha sucedido, todo lo que he hecho, todo lo que he pensado, todo lo que he sentido, no puedo inducirlo al error (...) aun cuando lo quisiera no lo lograría fácilmente de esta manera. A él le toca juntar todos estos elementos y determinar qué ser componen. El resultado debe ser su obra; si se equivoca, entonces todo el error será suyo. ${ }^{42}$

El relato al presentarse desarmado debería dejar al lector hacer el trabajo de reconstrucción, y permitir al autor reconquistar su unicidad por el trabajo de la lectura. Pero la empresa fracasa, a la lectura de las Confesiones responde un silencio cómplice..$^{43}$ Rousseau relata que en ese silencio incluso la emoción es sofocada. Ni el estilo desarmado de su prosa, ni la exposición a la cual el escritor somete al autor, logran romper el cerco que en torno a él levantó le público. El relato autobiográfico que debía interponerse entre la identidad del autor y la opinión para hacerlas confluir, es anulado por el silencio del público. La identidad del autor queda escindida entre el dominio

\footnotetext{
40 Confessions, p. 175.

${ }^{41}$ Confessions, p. 5.

42 Confessions, p. 175.

43 Confessions, p. 656.
} 
del escritor y el del público. El silencio que sigue a la lectura desconoce la soberanía del relato y reafirma paradójicamente la del autor sobre el texto. En efecto, el silencio que enfrenta al escritor con el público se sostiene de la preeminencia del autor sobre el relato. La verdad sigue estando en el autor y no en el texto. Sólo cuando el relato logre desenterrar al autor, caerá el dominio del público, y el escritor encontrara ante él el placer de la escritura. Ese proceso empieza, como veremos, en los Diálogos y culmina en las Ensoñaciones.

\section{El hombre de sus libros}

$\mathrm{Al}$ término de Las Confesiones Rousseau permanece "enlazado" 44 con el público. El escritor busco decirlo todo para reconstruir la unicidad del autor, pero el silencio que sigue a la lectura de las Confesiones da cuenta de que ésta permanece en manos del público. En las Confesiones el autor sigue teniendo las llaves de la obra y paradójicamente con ellas queda a merced del público. Decirlo todo es otra de las formas para el autor de afirmar su soberanía sobre el texto. En las Confesiones, la intimidad del autor, sacrificada sin pudor al público debe permitir restituir su identidad y a través de ella, la idoneidad de la obra. En los términos de Rousseau, la identidad del autor debe hacer justicia a la obra. Pero el público calla. Por su silencio, el público manifiesta que no renuncia a su dominio sobre la identidad del autor. Para despojar al público de su dominio, el escritor deberá renunciar a la soberanía del autor sobre la obra. En otras palabras, deberá dejar que el lector haga justicia. La aparición del lector libera al autor de la justificación de la obra y a la vez preludia el ocaso de su dominio. El proceso en el cual el autor va dejando su lugar al lector empieza en los Diálogos y culmina en las Ensoñaciones del paseante solitario. En este último apartado, nos dedicaremos a mostrar cómo la aparición del lector libera al escritor de los avatares de la condición de autor. Veremos que en los últimos escritos autobiográficos la identidad del autor se desdibuja. El autor empieza a funcionar como un nombre propio que identifica un conjunto de obras cuya identidad es un efecto de la lectura.

\footnotetext{
${ }^{44} \mathrm{El}$ verbo "enlacer" (enlazar) designa a lo largo de los Diálogos la relación del autor con el público: Rousseau se describe enlazado por el público.
} 


\subsection{Los Diálogos: la exacerbación del litigio}

Los Diálogos llevan al paroxismo el litigio sobre la identidad del autor; como las Confesiones, buscan justificar al autor para salvar la posteridad de la obra. Pero en ellos se extrema el litigio sobre la identidad. El nombre propio pierde su referencia unívoca. Rousseau y Jean-Jacques dejan de ser la misma persona. Si en las Confesiones Rousseau busca decirlo todo, en los Diálogos se muestra cómo se vería a sí mismo, si fuese otro. Toma el lugar del público para mostrar que otra perspectiva sobre él era posible: “(...) debía necesariamente decir cómo miraría, si fuese otro, un hombre tal como yo." 45

Rousseau asume la maleabilidad de la identidad derivada de la condición de autor. En los Diálogos Rousseau no es Rousseau, no se sabe quién es Jean-Jacques y por lo tanto tampoco quién es el autor de los libros que llevan su nombre. Los Diálogos ponen en escena el litigio sobre la identidad del autor alterando la identidad del nombre propio. Rousseau se explica en la introducción: "Me tomé la libertad de recuperar en estas conversaciones mi nombre de familia [el apellido] que el público creyó oportuno arrebatarme, y me designé en tercera persona por el de bautismo, al cual le gustó reducirme."46

El nombre del autor queda diseminado entre los personajes de los Diálogos: Rousseau, que no es el autor de los libros, y Jean-Jacques cuya autoridad sobre los libros está en duda. La intriga se construye a partir del enigma sobre la identidad de Jean-Jacques: ¿Jean-Jacques es el autor de los libros que llevan su nombre, o bien el autor de los crímenes que le imputa el público dirigido por Les Messieurs? ¿El autor de los libros y el autor de los crímenes pueden ser la misma persona?

Los personajes que integran el drama son cuatro: Rousseau, el Francés, el Público dirigido por Les Messieurs y Jean-Jacques. Los tres Diálogos que componen la obra ponen en escena la conversación de Rousseau, que leyó los libros y no conoce a su autor pero está convencido que no puede ser el autor de los crímenes que le imputa el público, con el Francés, que no leyó los

45 Dialogues, p. 665.

${ }^{46}$ Dialogues, p. 663 
libros ni conoce al autor, pero afirma, como lo hace el público, que el autor de los libros y el autor de los crímenes son la misma persona.

La conversación se organiza en torno a dos personajes extra-textuales enfrentados, Jean-Jacques y Les Messieurs, cuya presencia se manifiesta a través de la opinión del público. La opinión del público, asumida por el Francés en el primer diálogo, será finalmente desmentida en el último diálogo, aunque su dominio permanecerá inalterado.

Hay un quinto personaje que emerge en el transcurso de los Diálogos y que permitirá el desenlace del drama: el hombre de sus libros. Este último no es ni el autor, ni el escritor, ni tampoco Jean-Jacques; se desprende, como veremos, de la lectura de los libros, es creación del lector.

\subsection{La fuerza de la escritura}

El primer diálogo empieza con la execración de Jean-Jacques por parte de Rousseau-personaje. El Francés acaba de relatarle todos los crímenes que Les Messieurs le imputan a Jean-Jacques. La conversación entre ambos personajes se inicia en el marco de la teoría del genio que consagra la soberanía del autor sobre la obra. Es la identidad del autor, genial o perversa, la que decide acerca de la obra. Para el Francés, como para Les Messieurs, el alma criminal de Jean-Jacques destila en sus libros un veneno que es necesario prevenir. Desenmascarar al autor es el antídoto contra el veneno que esconden sus obras. Rousseau, que ha leído los libros, afirma que el autor de los libros y el autor de los crímenes no son la misma persona. La conclusión a la que llega es opuesta a la del Francés, pero subyace la misma lógica. La obra en un caso como en el otro refleja el alma del autor. El Francés va de la reputación de Jean-Jacques a la condena de los libros, el personaje Rousseau de los libros al alma del autor:

lo que no creo, y no creeré en mi vida, es que el Emilio y sobre todo el artículo sobre el gusto en el libro cuarto sean la obra de un corazón depravado (...), que el compendio entero de sus escritos haya salido de un alma hipócrita (...) y no de un corazón ardiente de amor por la virtud. (...) Pero digo y sostendré siempre que tiene que haber dos Jean-Jacques, 
y que el Autor de los libros y el de los crímenes no son el mismo hombre. ${ }^{47}$

La argumentación de Rousseau personaje se aparta sin embargo de la lógica de la teoría del genio. El personaje Rousseau va a fundamentar su convicción sin remitir a la identidad extra textual del autor. El alma del autor no remite a una identidad extra textual. El alma del autor no es el alma de Jean-Jacques. Recordemos que Rousseau-personaje no conoce a Jean-Jacques, sólo ha leído sus libros. El alma del autor se revela en la intensidad de la escritura. La fuerza de la escritura expresa una fuerza moral incompatible con las motivaciones de un canalla. La posibilidad de diferenciar el autor de los crímenes, del autor de los libros se configura en torno a la fuerza de la escritura. ${ }^{48}$

En efecto, en las primeras líneas del Diálogo el personaje Rousseau opone la fuerza de la escritura a la escritura afectada. Dónde el Francés ve "preceptos de virtud desplegados con tanto fasto", ${ }^{49}$ Rousseau corrige, "Diga 'fuerza'. Seamos justos incluso con los malos". Es la singularidad de la escritura que le permite al personaje Rousseau justificar la distinción entre el autor de los libros y el autor de los crímenes. Las dudas sobre la identidad de Jean-Jacques permanecen, pero lo que está fuera de duda para el personaje Rousseau es que el autor de los crímenes y el autor de los libros puedan ser la misma persona.

La distinción entre la identidad de Jean-Jacques y la autoría de los libros se radicaliza en el transcurso de los diálogos. Conocer a Jean-Jacques y conocer al autor de los libros se transforman en dos actos distintos. Sólo la lectura de los libros permite conocer al autor. Quien ha leído los libros sin reconocer los sentimientos del autor nunca podrá acercarse a él, como queda de manifiesto en la respuesta de Jean-Jacques al personaje Rousseau cuando éste le pide conocerlo.

47 Dialogues, p. 689-690.

${ }^{48}$ Debemos al maravilloso trabajo de Bento Prado Jr. el haber podido reconocer el rol conferido por Rousseau a la fuerza de la escritura: A retórica de Roussean e outros ensaios, Sao Paulo, Cosac Naify, 2008, pp. 129-172.

${ }^{49}$ Dialogues, p. 667. 
En términos ambiguos, Rousseau-personaje se dirige a Jean-Jacques con estas palabras: "si usted es el hombre de sus libros, ábrame la puerta con confianza". ${ }^{50}$ ¿Quién es el hombre de sus libros? ¿El escritor de los libros, o bien el hombre tal como se revela a la lectura de los libros? La respuesta de Jean-Jacques distingue y previene la confusión entre la realidad extra textual del escritor y la identidad del autor. La identidad del autor sólo se revela en la lectura: "Es usted el primero que el motivo que lo conduce lo haya traído hasta aquí: porque de tanta gente que tiene la curiosidad de verme, ninguno tiene la de conocerme; todos creen conocerme los suficiente. Venga pues, por la rareza del hecho". Agrega, sin embargo: "Pero ¿qué quiere usted de mí?, ¿y por qué me habla de mis libros? Si habiéndolos leído, lo han podido dejar con dudas sobre los sentimientos del Autor, no venga: en ese caso yo no soy su hombre, pues usted no sabría ser el mío". ${ }^{51}$

Se puede conocer a Jean-Jacques, pero no se puede conocer al autor de los libros a través de Jean-Jacques. La identidad del Autor es un efecto de la lectura. Si el lector no reconoció esas marcas de la escritura que develan el impulso que la inspira, entonces la lectura fue estéril y el autor quedara para siempre ausente. Si la lectura fue estéril "no soy su hombre, pues usted no sabría ser el mío” sentencia Jean-Jacques.

Pero Rousseau-personaje no va en busca del autor de los libros. Para él la identidad del autor no está en duda. Si busca a Jean-Jacques es porque quiere conocer al "hombre desfigurado" que imagina en su lugar. ${ }^{52}$ Lo que está en juego es la identidad de Jean-Jacques y no la del autor de los libros. El personaje Rousseau quiere saber si Jean-Jacques es el monstruo execrado por el público o bien un hombre desfigurado por el público. Para determinar quién es Jean-Jacques, realidad extra-textual, el relato autobiográfico introduce un personaje que sólo existe como efecto de la lectura: el hombre de sus libros.

El hombre de sus libros va a servir de tertium comparationis para determinar que Jean-Jacques no es el autor de los crímenes. El hombre de sus libros es la concepción del hombre que se desprende de la lectura de la obra

${ }^{50}$ Dialogues, p. 776.

${ }^{51}$ Dialogues, pp. 776-777.

52 Dialogues, p. 762. 
de Rousseau. El segundo diálogo a la vez que describe a Jean-Jacques retoma y profundiza la antropología de rousseauniana. El hombre de sus libros, que sólo un lector atento puede reconocer, no es ni un héroe, ni un monstruo. No es virtuoso pero su indolencia previene en él tanto las vilezas del vicio como las maquinaciones de la maldad. Al término de su visita Rousseau-personaje puede concluir que Jean-Jacques no es el autor de los crímenes pues ha reconocido en él al hombre de sus libros: "En una palabra, de la misma manera que he encontrado en sus libros al hombre de la naturaleza, he encontrado en él al hombre de sus libros sin necesidad de buscar expresamente si era verdad que fuese el Autor". 53

La identidad extra textual del autor se ha vuelto obsoleta. El texto autobiográfico que debía justificar al autor poco a poco se desprende de él. El hombre de sus libros, a la vez que permite discriminar entre Jean-Jacques y un criminal, va a permitir dar cuenta del autor sin remitir a su identidad extratextual. La identidad del autor, conquistada a través de sus libros, será en el último diálogo un efecto de la lectura.

Al final del primer diálogo el personaje Rousseau convence al Francés de leer los libros para comprobar por sí mismo su peligrosidad. Es el efecto de la lectura que debe persuadirlo si existe en ellos el veneno que Les Messieurs buscan prevenir: "Para eso, aconseja Rousseau, lea usted mismo los libros en cuestión, y de acuerdo a la disposición en que lo deje la lectura, juzgue sobre la del autor al momento de escribir (...)".54

Rousseau-personaje no busca que el Francés adopte su opinión sobre el autor, quiere que esa opinión sea un efecto de la lectura: "No piense en el Autor cuando los lea, y sin estar prevenido ni en su favor ni en su contra, abandone su alma a las impresiones que reciba. Se asegurará de esa manera, por usted mismo, de la intención en la que fueron escritos esos libros, y si pueden ser la obra de un canalla que cultiva malos propósitos." 55

En el último diálogo, el Francés relata su experiencia como lector de los libros tan difamados. El primer efecto de la lectura es permitirle reconocer

${ }^{53}$ Dialogues, p. 866.

${ }^{54}$ Dialogues, p. 697.

55 Dialogues, p. 699. 
la fuerza de la escritura y la intención que la guía. Lejos de encontrar en los libros las fastuosidades y el gusto por las paradojas que le reprochan Les Messieurs, el Francés descubre "una doctrina tan sana como simple, que sin epicureísmos y sin chismorreos sólo buscaba la felicidad del género humano." 56 A partir de esta primera lectura puede diferenciar al autor de los libros del autor de los crímenes.

La lectura de los libros permite al Francés reconocer a su autor, pero nada le dice sobre quién es Jean-Jacques, realidad extra-textual:

esta lectura, dejándome por uno de ellos la más sincera estima, me dejaba en cuanto al otro en la misma situación que antes (...). Los libros que me habían dicho ser peligrosos no lo eran: inspiraban sentimientos muy contrarios a aquellos que se le atribuía al autor, pero si Jean-Jacques no era el autor, en qué podrían servir a su justificación. ${ }^{57}$

Para decidir si Jean-Jacques es o no el autor de los crímenes que le imputa el público, el Francés emprende una segunda lectura, más atenta, de toda la obra. Esta segunda lectura no va buscar establecer en la identidad entre el autor y Jean-Jacques. El Francés se propone cotejar el relato que hace Rousseau de la personalidad de Jean-Jacques con la impresión sobre el autor que recibe de la lectura de los libros: "Creí que meditando muy atentamente sobre estas obras y comparando cuidadosamente al Autor con el hombre que usted me ha descripto, lograría esclarecer estos dos objetos el uno por el otro y asegurarme así si todo concuerda y pertenece a un mismo individuo." 58

El texto autobiográfico elude nuevamente la identificación directa entre el autor de los libros y Jean-Jacques realidad extra-textual. Esta segunda lectura no hace de Jean-Jacques el autor de los libros, descarta que sea el autor de los crímenes porque reconoce en el relato hecho por Rousseau-personaje al hombre natural que descubre en los libros. La segunda lectura del Francés explicita la ecuación entre el hombre de sus libros, el hombre natural y el autor de los libros: "Si usted no me hubiera descripto su Jean-Jacques, hubiera creído que el hombre natural ya no existía, pero la relación asombrosa

${ }^{56}$ Dialogues, p. 930.

${ }^{57}$ Dialogues, p. 931.

${ }^{58}$ Dialogues, p. 932. 
entre aquel que usted me describió y el Autor cuyos libros he leído no me dejan dudar que el uno es el otro, aunque no tuviera ninguna otra razón para creerlo." 59

La única razón para creer que "el uno es el otro" es un efecto de la lectura. La ecuación entre el autor de los libros y el hombre de sus libros se resuelve en el texto. El autor no es aquí la persona del escritor, es el hombre de sus libros. Conocer la persona del escritor, como conocer a Jean-Jacques se hace ahora superfluo. Después de esta segunda lectura el Francés rehúsa la necesidad de una prueba extra textual: "Usted pretende que debo ir a ver a Jean-Jacques para verificar por mis ojos lo que usted me ha dicho y lo que yo mismo he inferido a partir de la lectura de sus escritos. Esa confirmación es para mí superflua, y sin recurrir a ella sé de antemano a qué atenerme sobre ese punto". ${ }^{0}$

El lector afirma su soberanía sobre el texto. La identidad del autor ha quedado circunscripta a los márgenes del texto, sólo el ejercicio de la lectura les devolverá el espesor de la existencia: "Los libros mostrarán que el autor no fue tal como se esfuerzan en pintarlo". ${ }^{11}$

\section{E1 desenlace}

Al final de los Diálogos el escritor permanece sin embargo aferrado a la suerte del autor y así enlazado al público. Sordo a la autonomía que adquirió la obra, sigue esperando, "que su menoría sea restablecida un día en el honor que amerita, y que sus libros se vuelvan útiles por la estima debida a su Autor $(\ldots) "{ }^{62}$

Si, como hemos visto, los Diálogos ceden al espacio abierto por la lectura la verdad del texto, el escritor, todavía envuelto en la toga del autor, escribe para convencer al público. El escritor-autor, tal como un alma en pena, se resiste a partir y a abandonar el texto a sus lectores, sigue buscando

\footnotetext{
${ }^{59}$ Dialogues, p. 936.

${ }^{60}$ Dialogues, p. 939.

${ }^{61}$ Dialogues, p. 957.

${ }^{62}$ Dialogues, p. 976.
} 
el reconocimiento del público. Busca a través del lector ideal, confiable, no un ejercicio de lectura sino la confirmación de su identidad como clave del sentido del texto. El lector ideal y, a través de él, el público que se intenta convencer, es la imagen especular del autor soberano, para quien la verdad del autor es la verdad del texto. La historia de los Diálogos muestra de manera desesperada y grotesca que hasta que el autor no renuncie a "ramener le public" ${ }^{63}$ permanecerá enlazado con él.

La historia del presente relato ${ }^{64}$, escrita por Rousseau algunos meses después de terminados los Diálogos, da cuenta de las tribulaciones de esta alma en pena. En esa historia, Rousseau da cuenta de todos sus frustrados intentos por llegar al público: las rejas del altar de Notre Dame le impiden depositar en manos de la providencia su escrito; el desencuentro con el filósofo admirado -Condillac-, a quien confía los Diálogos con la esperanza de encontrar un lector pero que sólo ve en ellos una pieza de literatura que se puede mejorar armándola mejor; la loca idea de un "billet circulaire" que vendría a ser una nota, un papel, destinado a circular entre la gente en busca de un posible lector, pero que nadie quiere recibir; la reproducción indefinida del manuscrito para multiplicar sus rastros y llegar así a las generaciones futuras en busca del lector.

Las tribulaciones de esa desesperada búsqueda por hacer coincidir la imagen de la opinión con la imagen que el autor tiene de sí, bruscamente se interrumpen. El recuerdo de otro texto, Emilio, ${ }^{65}$ hace que el autor renuncie al reconocimiento del público: “¿He pues reconocido la vanidad de la opinión sólo para someterme a su yugo en desmedro de la paz de mi alma y la tranquilidad de mi corazón?”"66

\footnotetext{
63 Rêveries, p. 997. Poner al público de su lado, literalmente: "volver a traer a sî".

${ }^{64}$ Rousseau, Histoire du précédent écrit, Euvres complètes I, Paris, Gallimard, 1959, pp. 977-989.

65 "Un pasaje del Emilio que recordaba me hizo entrar en mí y encontrar en mí lo que había buscado vanamente fuera de mí. ¿Qué mal te ha hecho este complot? ¿Qué ha tomado de ti? ¿Qué miembro te ha mutilado? ¿Qué crimen te ha hecho cometer?" (Histoire du précédent écrit, p. 985).

66 Ibid.
} 
En esa cesura del relato autobiográfico se desata definitivamente el nudo que unía dramáticamente la identidad del escritor con la suerte del autor. El escritor vuelve en sí, el autor desaparece, el relato autobiográfico se transforma.

En las Ensoñaciones del paseante solitario el escritor, sin el lazo que lo unía al público, queda solo. ${ }^{67}$ Solo, es decir sin ellos, el público. Liberado del lazo que lo ligaba con "ellos" desaparece también la certeza sobre la identidad: "¿Pero yo separado (détaché) de ellos y de todo quién soy?"68. El motivo del relato autobiográfico ya no es como en las Confesiones decirlo todo para que el lector pueda reconstruir la verdad sobre el autor, sino conocerse a sí mismo: "Consagraré mis últimos días a estudiarme a mí mismo." 69

En esta búsqueda la escritura vuelve a ser protagonista. Como en las Confesiones y en los Diálogos aparece despojada de los artificios de la literatura. "Estas hojas no serán, propiamente, más que un informe diario de mis ensoñaciones"..$^{70}$ Pero a diferencias de los textos anteriores, en las Ensoñaciones la escritura deja de ser la garantía de verdad, y el lugar del sufrimiento. La escritura despojada del cuidado de la forma y sin la carga de la verdad se transforma en fruición. Las Ensoñaciones no están escritas para decir la verdad sobre el autor sino para preservar el deleite del escritor: "Las distracciones (loisirs) de mis paseos diarios a menudo han estado pobladas de encantadoras contemplaciones cuyo recuerdo lamento haber perdido. Fijaré por la escritura aquellas que todavía puedan acontecer; cada vez que las vuelva a leer, la escritura] me devolverá el deleite". ${ }^{71}$

El placer de la escritura trasciende y a la vez hace posible el placer de la rememoración. El placer no está en el recuerdo de la experiencia vivida sino en la presencia que adquiere en el acto de escribir: "su lectura me recordará el

\footnotetext{
${ }^{67}$ Rêveries, p. 995: "Heme aquí solo sobre la tierra [...]" son las primeras palabras de las Ensoñaciones.

${ }^{68}$ Rêveries, p. 995. Détaché: literalmente, desatado.

${ }^{69}$ Rêveries, p. 999.

${ }^{70}$ Rêveries, p. 1000.

${ }^{71}$ Rêveries, p. 999.
} 
placer (douceur) que disfruté al escribirlas, y haciendo renacer de esa manera el tiempo pasado, duplicará por así decirlo mi existencia."72

El escritor se ha enlazado definitivamente al placer de la escritura a tal punto que la materialidad y la posteridad del texto se han vuelto obsoletas:

Fui escribiendo mis primeras Confesiones y mis Diálogos con la preocupación constante de ocultarlos a las manos rapaces de mis perseguidores para transmitirlos si fuera posible, a otras generaciones. La misma inquietud ya no me atormenta en este escrito, sé que sería inútil, y el deseo de ser mejor conocido por los hombres habiéndose apagado en mi corazón, no deja más que una indiferencia profunda sobre la suerte de mis verdaderos escritos y de los monumentos de mi inocencia, que quizás ya han sido aniquilados para siempre. (...) Ni las escondo (las hojas) ni las enseño. Si me las quitan en vida, no me quitarán ni el placer de haberlas escrito, ni el recuerdo de su contenido $(. ..) .^{73}$

El autor ha desertado definitivamente; el texto, la lectura y el placer de la escritura han tomado su lugar.

Terminaré este trabajo con unas líneas del diálogo ficticio con el cual Foucault cierra su introducción a los Diálogos:

- ¿Los Diálogos no son la obra de un loco?

-Esa pregunta importaría si tuviera sentido; pero la obra es, por definición, no-locura.

-La estructura de una obra puede sin embargo, dejar aparecer el bosquejo de una enfermedad.

-Es decisivo que la recíproca no sea verdad. ${ }^{74}$

Recibido: 09/2016; aceptado: 12/2016

72 Rêveries, p. 1001.

73 Rêveries, p. 1001.

${ }^{74}$ Foucault, M., Introduction a Rousseau Juge de Jean-Jacques. Dialogues. Paris, A. Colin, 1962, pp. VII-XXIV. 